\section{SAT0046 MODIFIED DISEASE ACTIVITY SCORE AT 3 MONTHS IS A SIGNIFICANT PREDICTOR FOR RAPID RADIOGRAPHIC PROGRESSION AT 12 MONTHS COMPARED WITH OTHER MEASURES}

M. Movahedi ${ }^{1,2}$, D. Weber ${ }^{1}$, P. Akhavan ${ }^{1}$, E. Keystone ${ }^{1} .{ }^{1}$ Division of Rheumatology, Mount Sinai Hospital, Toronto, Canada; ${ }^{2}$ Institute of Health Policy, Management and Evaluation, University of Toronto, Toronto, Canada

Background: Progressive rheumatoid arthritis (RA) is responsible for joint damage causing disabilities with no agreement on which disease measures best predict radiographic progression

Objectives: We aimed to determine which disease activity measures including disease activity score (DAS), modified (M) DAS28 (CRP), clinical disease activity index (CDAI), and health assessment questionnaire disability index (HAQ-DI) best predict rapid radiographic progression (RRP) in early RA patients at baseline $(\mathrm{BL})$ and 3 months.

Methods: PREMIER data, a 2-year, multicenter, double-blind active comparator-controlled study with methotrexate (MTX) naïve RA patients and active disease $<3$ years, were used. Only patients in the MTX arm were analyzed. RRP was defined as change in modified total Sharp (mTSS) $>3.5$ at month 12. Logistic regression analysis assessed impact of measures at BL and 3 months on RRP at 12 months. Best cut-off points of M-DAS28(CRP) was also estimated using area under the receiver operating characteristic curve.

Results: 149 patients were included: female $(n=113 ; 75.8 \%)$, positive RF $(n=127 ; 85.2 \%)$, mean (SD) age 52.9 (13.3) years, disease duration $0.8(0.9)$ year, DAS28(CRP) 6.3 (0.9). After adjusting for potential confounders, only M-DAS28(CRP) at BL $\left.{ }_{\text {adj }} \mathrm{OR}=3.29 ; 95 \% \mathrm{Cl}: 1.70-6.36\right)$ and 3 months $\left({ }_{\text {ad }} \mathrm{OR}=2.56\right.$ $95 \% \mathrm{Cl}: 1.43-4.56$ ) strongly predicted RRP at 12 months. M-DAS28(CRP) 4.5 and 2.6 at $\mathrm{BL}$ and 3 months maximized sensitivity and specificity for prediction of RRP.

Conclusion: M-DAS28(CRP) was a stronger predictor at BL and 3 months for RRP compared with other disease activity measures. Removing tender join count and patient global assessment from DAS28(CRP) improves prediction of RRP.

References:

[1] Breedveld FC, Weisman MH, Kavanaugh AF, Cohen SB, Pavelka K, van Vollenhoven R, et al. The PREMIER study: A multicenter, randomized, double-blind clinical trial of combination therapy with adalimumab plus methotrexate versus methotrexate alone or adalimumab alone in patients with early, aggressive rheumatoid arthritis who had not had previous methotrexate treatment. Arthritis and rheumatism. 2006;54(1):26-37.

Acknowledgments : The authors wish to knowledge AbbVie Canada Inc. for providing patients data.

Disclosure of Interests: Mohammad Movahedi Consultant of: Allergan, Deborah Weber: None declared, Pooneh Akhavan: None declared, Edward Keystone Grant/research support from: AbbVie; Amgen; Gilead Sciences, Inc; Lilly Pharmaceuticals; Merck; Pfizer Pharmaceuticals; PuraPharm; Sanofi, Consultant of: AbbVie; Amgen; AstraZeneca Pharma; Bristol-Myers Squibb Company; Celltrion; F. Hoffman-La Roche Ltd.; Genentech, Inc; Gilead Sciences, Inc.; Janssen, Inc; Lilly Pharmaceuticals; Merck; Myriad Autoimmune; Pfizer Pharmaceuticals, Sandoz, Sanofi-Genzyme, Samsung Bioepsis., Speakers bureau: AbbVie; Amgen; Bristol-Myers Squibb; Celltrion; F. Hoffman-La Roche Ltd, Janssen, Inc; Merck; Pfizer Pharmaceuticals; Sanofi-Genzyme; UCB DOI: 10.1136/annrheumdis-2020-eular.1762

\section{SAT0047 \\ RISK FACTORS FOR THE POSTOPERATIVE DELAYED WOUND HEALING IN PATIENTS WITH RHEUMATOID ARTHRITIS TREATED WITH A BIOLOGICAL AGENT}

S. Okita ${ }^{1,2,3}$, H. Ishikawa ${ }^{2}$, A. Abe ${ }^{2}$, S. Ito ${ }^{2}$, A. Murasawa ${ }^{2}$, K. Nishida ${ }^{3}$, T. Ozaki ${ }^{3}$. ${ }^{1}$ Okayama City Hospital, Orthopedic Surgery, Okayama, Japan; ${ }^{2}$ Niigata Rheumatic Center, Rheumatology, Shibata, Japan; ${ }^{3}$ Okayama University Graduate School of Medicine, Dentistry, and Pharmaceutical Sciences, Orthopedic Surgery, Okayama, Japan

Background: It has been suggested that perioperative use of biological disease-modifying anti-rheumatic drugs (bDMARDs) in rheumatoid arthritis (RA) patients carries risks for the surgical-site infection and the delayed wound healing (DWH); however, the risk of DWH with perioperative use of bDMARDs has not reached a general consensus.

Objectives: This retrospective study aimed to investigate the risk factors associated with DWH after orthopedic surgery in RA patients treated with bDMARDs. Methods: We reviewed medical records of 277 orthopedic procedures for 188 RA patients treated with bDMARDs between from 2014 to 2017 in Niigata Rheumatic Center. As preoperative nutritional status assessment, we evaluated body mass index (BMI), prognostic nutritional index (PNI), and CONtrolling NUTritional status (CONUT). In addition, we evaluated DAS28-CRP, DAS28-ESR, face scale for pain, global health $(\mathrm{GH})$, and Health Assessment Questionnaire-Disability
Index (HAQ-DI) to assess the disease activity. Univariate and multivariate logistic regression analyses were performed to evaluate the risk factor for $\mathrm{DWH}$.

Results: The major characteristics of the patients in 277 procedures were mean age of 63.2 years old and mean disease duration of 18.2 years. Surgical site were hand and wrist (145 procedures), foot and ankle (76), hip and knee (31) elbow and shoulder (24), and spine (1). Seventy-four patients were treated with tocilizumab, 62 with etanercept, 55 with golimumab, 49 with abatacept, 16 with infliximab, 15 with adalimumab, and 6 with certolizumab. According to nutritional assessment in PNI and CONUT, 63\% $(n=175)$ and $47 \%(n=130)$ were normal nourished patients, respectively.

In 277 procedures, DWH were identified in 24 patients (8.6\%). The following variables were significant in the univariate analyses: disease duration (OR 1.053; 95\% Cl 1.010-1.099; $\mathrm{p}=0.016$ ), foot and ankle surgery (OR 7.091; 95\% Cl 2.130-23.603; $p=0.001$ ), tocilizumab (OR $0.286 ; 95 \%$ Cl $0.093-0.881$ $\mathrm{p}=0.029$ ) (Table 1). These variables were entered into a multivariate model, and it was revealed that pre-operative use of tocilizumab (OR $0.265 ; 95 \% \mathrm{C}$ $0.074-0.953 ; p=0.042$ ) and procedures in the foot and ankle (OR 6.915; 95\% $\mathrm{Cl}$ 1.914-24.976; $\mathrm{p}=0.003$ ) were associated with an increased risk of $\mathrm{DWH}$ (Table 1).

Conclusion: As previous study on tocilizumab described, the current retrospective study suggested that pre-operative use of tocilizumab and procedures in the foot and ankle were risk factors for DWH. Pre-operative disease activity and nutritional status were not independent risk factors for an increase in the prevalence of DWH.

\section{References:}

[1] Momohara S, Hashimoto J, Tsuboi $\mathrm{H}$ et al. Analysis of perioperative clinical features and complications after orthopaedic surgery in rheumatoid arthritis patients treated with tocilizumab in a real-world setting: Results from the multicentre tocilizumab in perioperative period (TOPP) study. Modern rheumatology. 2013, 23: 440-9.

Table 1. Risk factors for DWH after orthopedic surgery in RA patients treated with bDMARDs

\begin{tabular}{lcccc}
\hline \multicolumn{2}{c}{ Univariable } & \multicolumn{2}{c}{ Multivariable } \\
\hline & OR $(95 \% \mathrm{Cl})$ & $\mathrm{p}$ value & OR $(95 \% \mathrm{Cl})$ & $\mathrm{p}$ value \\
\hline Age & $1.012(0.967-1.059)$ & 0.610 & & \\
Disease duration & $1.053(1.010-1.099)$ & 0.016 & $1.035(0.980-1.093)$ & 0.220 \\
Surgical site & & & ref & \\
hand and wrist & Ref & & n.c. & \\
elbow and shoulder & n.c. & & n.c. & \\
hip and knee & n.c. & & & \\
foot and ankle & $7.091(2.130-23.603)$ & 0.001 & $6.915(1.914-24.976)$ & \\
Smoking & $0.708(0.085-5.905)$ & 0.749 & & \\
Diabetes Mellitus & $0.698(0.150-3.252)$ & 0.647 & & \\
DAS28-CRP & $0.558(0.302-1.029)$ & 0.062 & & \\
HAQ-DI & $0.986(0.923-1.054)$ & 0.686 & & \\
use of PSL & $1.039(0.343-3.147)$ & 0.946 & & \\
bDMARDs & & & & \\
TNF inhibitors & ref & & & \\
tocilizumab & $0.286(0.093-0.881)$ & 0.029 & $0.265(0.074-0.953)$ & 0.042 \\
abatacept & $0.370(0.072-1.889)$ & 0.232 & $0.515(0.085-3.107)$ & 0.469 \\
PNI & $0.986(0.896-1.084)$ & 0.767 & & \\
CONUT & $0.892(0.594-1.338)$ & 0.580 & & \\
& & & &
\end{tabular}

Disclosure of Interests: Shunji Okita: None declared, Hajime Ishikawa: None declared, Asami Abe: None declared, Satoshi Ito Speakers bureau: Abbvie,Eisai, Akira Murasawa: None declared, Keiichiro Nishida Grant/research support from: K. Nishida has received scholarship donation from CHUGAI PHARMACEUTICAL Co., Eisai Co., Mitsubishi Tanabe Pharma and AbbVie GK., Speakers bureau: K. Nishida has received speaking fees from CHUGAI PHARMACEUTICAL Co., El Lilly, Janssen Pharmaceutical K.K., Eisai Co. and AYUMI Pharmaceutical Corporation., Toshifumi Ozaki: None declared

DOI: 10.1136/annrheumdis-2020-eular.3424

\section{SAT0048 \\ THE CLINICAL USE OF F-18 NAF BONE PET/CT FOR EVALUATING DISEASE ACTIVITY IN PATIENTS WITH RHEUMATOID ARTHRITIS}

H. J. Park ${ }^{1}$, J. W. Lee ${ }^{2} .{ }^{1}$ International St. Mary's Hospital, Catholic Kwandong University College of Medicine, Internal Medicine, Incheon, Korea, Rep. of (South Korea); ${ }^{2}$ International St. Mary's Hospital, Catholic Kwandong University College of Medicine, Nuclear Medicine, Incheon, Korea, Rep. of (South Korea)

Background: Bone positron emission tomography/computed tomography (PET/ $\mathrm{CT}$ ) using $\mathrm{F}$-18 sodium-fluoride ( $\mathrm{NaF}$ ) has been widely used in various bone and joint diseases. However, only a few studies had evaluated the clinical implication of $\mathrm{F}-18 \mathrm{NaF}$ bone PET/CT in patients with rheumatoid arthritis ${ }^{1}$. 